\title{
CORRIGENDUM
}

\section{Partial USH2A deletions contribute to Usher syndrome in Denmark}

Shzeena Dad, Nanna D Rendtorff, Erik Kann, Anders Albrechtsen, Mana M Mehrjouy, Mads Bak, Niels Tommerup, Lisbeth Tranebjærg, Thomas Rosenberg, Hanne Jensen and Lisbeth B Møller

European Journal of Human Genetics (2015) 23, 1750; doi:10.1038/ejhg.2015.131

Correction to: European Journal of Human Genetics (2015) 23, 1646-1651; doi:10.1038/ejhg.2015.54; published online 25 March 2015
Post online publication it was realised that one of the author's names (Shzeena Dad) had been submitted incorrectly. This has now been rectified.

\section{ERRATUM}

\section{Biallelic RFX6 mutations can cause childhood as well as neonatal onset diabetes mellitus}

Francis H Sansbury, Birgül Kirel, Richard Caswell, Hana Lango Allen, Sarah E Flanagan, Andrew T Hattersley, Sian Ellard and Charles J Shaw-Smith

European Journal of Human Genetics (2015) 23, 1750; doi:10.1038/ejhg.2015.208

Correction to: European Journal of Human Genetics (2015) 23, 1744-1748; doi:10.1038/ejhg.2015.161; published online 12 August 2015

Hana Lango Allen's last names were transposed when the above paper was published online.
Hana Allen Lango should have read as Hana Lango Allen. The Publishers apologise for their error. 